\begin{tabular}{c} 
REVISTA EVIDENCIAÇÃO CONTÁBIL \& FINANÇAS \\
João Pessoa, v. 7, n.3, p. 105 -126, Set./Dez. 2019. ISSN 2318-1001 \\
DOI: 10.22478/ufpb.2318-1001.\%Yv\%vn\%i.41207 \\
Disponível em: http://periodicos.ufpb.br/ojs2/index.php/recfin \\
\hline
\end{tabular}

\title{
DEFICIÊNCIAS DOS CONTROLES INTERNOS DAS EMPRESAS LISTADAS NA[B3] ${ }^{1}$
}

\author{
INTERNAL CONTROL WEAKENESSES OF LISTED COMPANHIES IN [B3]
}

\author{
Isabella Mariana de Oliveira Lopes \\ Bacharel em Ciências Contábeis pela PUC Minas \\ bella marianalopes@hotmail.com \\ Vagner Antônio Marques \\ Doutor em Administração (Finanças) pela UFMG \\ Universidade Federal do Espírito Santo \\ vagner.marques@ufes.br \\ Luiz Cláudio Louzada \\ Doutor em Administração (Finanças) pela UFMG \\ Universidade Federal do Espírito Santo \\ louzadalvi@yahoo.com.br
}

\section{RESUMO}

Objetivo: O presente estudo identificou os tipos de deficiências de controles internos reportados pelas empresas participantes da carteira teórica do IBOVESPA.

Método: A pesquisa de natureza descritiva, documental e com abordagem quali-quanti analisou dados referentes ao período de 2010-2015 de 32 empresas listadas na [B] $]^{3}$. Os dados foram coletados nos Formulários de Referência disponíveis no sítio eletrônico da CVM, sendo aplicado análise de conteúdo, estatística descritiva e o Teste Kruskal-Wallis para diferenças entre os grupos. As categorias utilizadas foram as mesmas de Ge \& McVay (2005) de modo a possibilitar a comparabilidade entre as pesquisas.

Resultado: Os resultados evidenciaram que $87 \%$ das deficiências reportadas com informações suficientes para categorizá-las referiram-se a: (i) Treinamento - 23\%, (ii) Falhas Tecnológicas - 20\%, (iii) Falhas em Subsidiárias - 17\%, (iv) Contas Específicas - 15\% e (v) Segregação de Funções - 12\%. Além disso, das 270 deficiências reportadas, 132 não apresentaram detalhamentos suficientes para identificá-las, o que sugere necessidade de maior intervenção por parte dos reguladores.

\footnotetext{
${ }_{1}^{1}$ Artigo recebido em: 04/08/2018. Revisado por pares em: 30/10/2018. Reformulado em: 15/02/2019. Revisado por pares em: 28/03/2019. Recomendado para publicação: 03/05/2019 por Luiz Felipe de Araújo Pontes (Editor Geral). Publicado em: 02/09/2019. Organização responsável pelo periódico: UFPB
} 
Contribuições: $\mathrm{O}$ estudo contribui com a literatura sobre o tema, analistas e reguladores na medida em que apresenta um panorama das deficiências dos controles internos reportadas pelas empresas com maior volume de negociações em bolsa na $[\mathrm{B}]^{3}$.

Palavras chave: Controles Internos, Estrutura de Governança, Auditoria.

\section{ABSTRACT}

Objectives: The present study identified the types of internal controls weaknesses reported by the companies participating in the theoretical portfolio of the IBOVESPA.

Methods: The descriptive, documental and quali-quanti approach analyzed data for the 2010-2015 period of 32 companies listed on $[\mathrm{B}]^{3}$. The data were collected in the references form available on the CVM website and content analysis, descriptive statistics and the Kruskal-Wallis test were used for differences between groups. The categories used were the same as those of Ge \& McVay (2005) in order to allow comparability between the surveys.

Results: The results showed that $87 \%$ of the internal controls weaknesses reported with sufficient information to categorize them referred to: (i) Training - 23\%, (ii) Technological Failures - 20\%, (iii) Failures in Subsidiaries - 17\% ) Specific Accounts - 15\% and (v) Segregation of Functions - 12\%. In addition, of the 270 internal controls weaknesses reported, 132 did not present sufficient details to identify them, suggesting a need for greater intervention by regulators.

Contributions: The study contribute with literature about theme, analysts and regulators in that it presents an overview of intern control weaknesses reported by the companies with the highest trading volume.

Keywords: Internal Control Weaknesses, Structural of Governance, Auditing.

\section{INTRODUÇÃO}

A divulgação de informações financeiras consiste em uma forma dos provedores de capital ajustarem suas expectativas aos retornos das empresas (companhias) na medida em que possibilita a avaliação de desempenho e a tomada de decisões sobre comprar, vender, negociar, terceirizar, etc. (Ball \& Brown, 1968; Beaver, 1968). Ocorre que a divulgação das informações de per si não garante sua fidedignidade pois comportamentos associados ao conflito de agência podem resultar em gerenciamento de resultados e/ou fraudes contábeis dependendo do caso (Jensen \& Meckling, 1994). A crise de 1929, o caso Enron, entre outros, reforçam a ocorrência desse tipo de evento (Di Pietra, McLeay, \& Ronen, 2014).

As empresas necessitam criar mecanismos para monitorar e alinhar os interesses dos gestores com os dos acionistas (Jensen \& Meckling, 1976). Esses mecanismos são denominados de Estrutura de Governança. De acordo com Brickley \& Zimmerman (2010), a estrutura de governança refere-se a todo instrumento contratual, interno ou externo que busca alinhar os interesses das partes envolvidas, sobretudo principal-agente. Consistem em contratos, sistemas, órgãos e/ou processos que reduzam as chances dos gestores (agentes) expropriarem recursos dos acionistas (principais) com vistas a atenderem seus próprios 
interesses.Tais instrumentos tem por propósito dar maior transparência ao processo de gestão e na relação agente-principal.

A estrutura de governança é referida como aquela que inclui o conselho de administração, conselho fiscal, comitê de auditoria, estrutura de propriedade, etc. (Brown \& Caylor, 2009). Mas não apenas, os sistemas de controles utilizados pelas companhias são incluídos na estrutura de governança corporativa, pois possibilitam monitorar e controlar o funcionamento dos recursos sob responsabilidade dos gestores, potencializando uma maior tranparência e alinhamento aos objetivos dos acionistas e as metas das empresas. Sua importância é tamanha que a Sarbanes-Oxley Act (SOX) estimulou a tranparência e o accountability das empresas por meio dos Controles Internos (Borgerth, 2012).

Marques et al. (2016, p.42) afirmam que "os controles internos estabelecem as normas e procedimentos específicos a serem utilizados pelos empregados e gestores no desenvolvimento das suas atividades". De acordo com Doyle, Ge, \& McVay (2007), a adequada estruturação de um sistema de controle interno tende a reduzir: (i) a ocorrência de fraudes e erros, (2) o risco e custos de auditoria, (3) os custos de agência, (4) republicação das demonstrações, entre outros.

Di Pietra \& Ronen (2014) afirmam que o caso Enron expôs a relevância do monitoramento dos gestores quanto à forma como realizam suas atividades. Isso implicou na promulgação da SOX que estabeleceu princípios para a estruturação dos controles internos das firmas de modo a torná-los mais robustos e rígidos.

No contexto brasileiro, os órgãos reguladores e instituições públicas e privadas seguiram a mesma lógica. A Comissão de Valores Mobiliários (CVM), o Conselho Federal de Contabilidade (CFC), o Instituto dos Auditores Independentes do Brasil (IBRACON), a [B] ${ }^{3} \mathrm{e}$ o Instituto Brasileiro de Governança Corporativa (IBGC), entre outros, têm estimulado a adoção e práticas de governança que fortalecem a estrutura de controles internos.

No âmbito do CFC, a Norma Brasileira de Contabilidade Técnica da Auditoria (NBC TA) 265 - Comunicação de Deficiências de Controle Interno estabelece que os auditores deverão comunicar as fragilidades de controles internos significativas identificadas. Tal determinação é acompanhada pelos reguladores como a CVM que exige a divulgação (no relatório circunstanciado) das deficiências de controles internos identificadas pelo auditor.

Deste modo, desde 2010, as empresas brasileiras listadas na $[\mathrm{B}]^{3}$ ficaram obrigadas a divulgar no Formulário de Referência da CVM, informações relativas às deficiências identificadas. Trata-se de um mecanismo de monitoramento de falhas eventuais ou recorrentes e que melhoram a avaliação por parte dos provedores de capital acerca das empresas. Como trata-se de uma divulgação relativamente recente, os estudos empíricos nacionais sobre o tema são relativamente escassos (Teixeira \& Cunha, 2016). Estudos internacionais realizados, como o de Ge e McVay (2005), por exemplo, buscaram analisar os tipos de deficiências nos controles internos de 275 empresas após a adoção da SOX. Neste contexto, dada a escassez de estudos com essa finalidade, o presente estudo buscou responder a seguinte questão: Quais os tipos de deficiências de controles internos reportadas pelas empresas participantes do IBOVESPA?

O objetivo do estudo foi identificar os tipos de deficiências de controles internos reportadas pelas empresas brasileiras listadas na $[\mathrm{B}]^{3}$ e que fizeram parte do IBOVESPA no último trimestre de 2015. O estudo de natureza descritiva, documental e com abordagem 
quali-quanti analisou dados 32 empresas no período de 2010-2015 e foram analisados através de análise de conteúdo, estatística descritiva e teste de homogeneidade.

O presente estudo contribui para compreender quais os principais problemas identificados e divulgados pelas empresas no contexto brasileiro. A compreensão desse fenômeno pode, entre outras, implicar: (i) maior atenção dos reguladores junto aos agentes econômicos, (ii) maior monitoramento dos auditores externos, (iii) estabelecimento de políticas que reforcem a relevância dos controles internos, dentre outros.

Além da seção referente a introdução, o presente estudo possui 4 seções, sendo a seção dois aquela em que se apresentou a revisão da literatura sobre o tema. Na seção três, apresentou-se os procedimentos metodológicos aplicados ao estudo. Na seção quatro, apresentou-se a análise dos dados e resultados do estudo, por fim, na seção cinco, apresentou-se as considerações finais e sugestões para estudos futuros.

\section{REFERENCIAL TEÓRICO}

\subsection{Teoria de Agência, Governança Corporativa e Estrutura de Controles Internos}

Os problemas de agência podem ser conceituados como todo e qualquer comportamento dos agentes que vise atender suas expectativas e contrarie aos interesses dos acionistas direta ou indiretamente (Aghion \& Holden, 2011). Os gestores podem, por exemplo, alterar a política de contabilização de determinado evento econômico (depreciação, perdas estimadas com créditos de liquidação duvidosa, perdas por não recuperabilidade de ativos, dentre outros) visando aumentar seu pacote de remuneração variável, reduzir a variabilidade do lucro, ou ainda atender às expectativas dos analistas (Dye \& Sridhar, 2008; Aghion \& Holden, 2011).

A Teoria da Agência de Jensen e Meckling, 1976 preconiza que os gestores (agentes) poderão agir oportunisticamente em relação aos principais (acionistas, por exemplo). Tal expectativa tem implicações relevantes na forma como os acionistas se relacionam com os gestores, pois, os agentes, como avaliadores, criativos, maximizadores e com desejos ilimitados que possuem (Jensen \& Meckling, 1994) podem tomar decisões que contrariem as expectativas dos acionistas, gerando, inclusive perda de valor. Desse modo, as empresas, como um nexo de contratos que visam a maximização, precisam buscar mecanismos contratuais para mitigarem a ocorrência desses eventos, denominados, de problemas de agência.

De acordo com Jensen e Meckling (1976), os problemas de agência geram custos, denominados de custos de agência, logo, gastos com sistemas de controle, com auditoria, pacotes de remuneração serão necessários para que se mitigue sua ocorrência. Os autores argumentam que a incorrência de custos de agência é, no limite, uma necessidade que pode gerar benefícios aos acionistas, pois eles reduzem as chances dos indivíduos agirem oportunisticamente e estimulam uma gestão de forma mais transparente, logo, podem inclusive gerar valor ao acionista.

A implantação de mecanismos que reduzem as chances dos gestores agirem de modo que contrariem os interesses dos acionistas é necessária. Esses mecanismos são denominados de Estrutura de Governança. De acordo com Brickley e Zimmerman (2010, p.236), a estrutura de governança é usualmente definida como conjunto de contratos que buscam alinhar as 
escolhas e decisões dos gestores aos interesses dos acionistas. Na prática, todo mecanismo que estimula o "enforcement" e o "accountability" das companhias pode ser considerado como um instrumento de governança. Entretanto, o foco tem sido dado aos instrumentos contratuais que minimizem o risco de expropriação associado à separação entre propriedade e controle, pois segundo La Porta et al. (1998), a Governança Corporativa refere-se aos acordos firmados pelos provedores de capital que visam assegurar o retorno dos seus investimentos.

Dentre os diversos instrumentos de governança utilizados, destacam-se: (i) a estrutura de propriedade; (ii) independência do conselho fiscal e de administração; e (iii) existência de comitê de auditoria, etc. De acordo com Hay, Knechel e Ling (2008), Hammersley, Myers, e Shakespeare (2008) e Mitra e Hossain (2011), essa estrutura de governança tem efeito positivo sobre a qualidade da auditoria, a estrutura do controle interno e por sua vez, reduzem os custos de agência e geram valor.

De acordo com a AICPA - American Institute of Certified Public Accountants (2016), os controles internos podem ser definidos como aqueles instrumentos e sistemas desenvolvidos com a finalidade de se mitigar riscos operacionais que impliquem em fraudes ou erros. Eles possibilitam que as operações realizadas pela companhia sejam completas e adequadamente divulgadas, detectando-se previamente a ocorrência de tais eventos e propondo soluções para corrigi-las. Dada sua relevância, a divulgação de deficiências de controles internos identificadas é de suma importância. Segundo Hammersley, Myers e Shakespeare (2008), a divulgação acerca de fragilidades identificadas nos controles internos tem efeito sobre o comportamento dos preços das ações.

Por um lado, quando a companhia divulga uma fragilidade relevante não esperada pelos provedores de capital, os preços tendem a reduzir-se como reflexo de uma superavaliação por parte dos mesmos já que desconsideraram essas deficiências no cálculo do risco. Por outro, a correção (remediation) posterior evidencia o compromisso dos gestores em solucionar os problemas gerando maior confiança nos provedores de capital, o que implicará em menor percepção de risco e aumento de valor dos preços (Cheng, Dhaliwal, \& Zhang, 2013).

Desse modo, a preocupação com a adequada estruturação do sistema de controle interno é constante. Fourie e Ackermann (2013), argumentam que desde os casos de fraudes ocorridos por volta dos anos 2000, que geraram grandes perdas aos investidores, as empresas, órgãos não governamentais e reguladores têm destinado esforços para estimular a adequada estruturação dos controles internos. Segundo Tysiac (2012), por 20 anos, o framework do Committee of Sponsoring Organizations of Treadway (COSO) foi utilizado como base. Suas diretrizes estabelecem que no processo de estruturação do sistema de controle interno as empresas deverão se preocupar: (1) com a eficiência e eficácia operacional, (2) confiabilidade das informações e prestações de contas e, (3) conformidade ou cumprimento das exigências legais, éticas e morais.

Ritemberg (2013) observa que o framework do COSO teve relevantes alterações a partir de 2013 em função de mudanças no ambiente de negócios. Fatores como riscos tecnológicos, mudanças na estrutura de governança, aumento da interdependência das organizações, aumento da demanda informacional (interna e externa), maior foco na gestão de riscos e aumento da importância do compliance e atividades operacionais fizeram com que o framework de 1992 fosse revisto. Isso significou uma maior preocupação da integração entre 
os diversos instrumentos de governança internos e externos e, a estrutura de controles internos.

Conforme se observa na Figura 1, a estrutura de mercado, a estrutura de governança e o ambiente regulatório estimulam os agentes econômicos a desenvolverem controles internos mais robustos, exigindo, portanto, maior julgamento por parte dos gestores, contadores e profissionais envolvidos. A eficiência (e eficácia), a confiabilidade e a conformidade devem ser buscadas através da estrutura de controle internos sempre com observância às variáveis relevantes ao longo do tempo, o que significa que o julgamento é uma premissa permanente no processo, sobretudo a partir da revisão do COSO 2013. Tysiac (2012) afirma que os princípios básicos do Framezork do COSO considera: (1) o ambiente de controle, (2) gestão de riscos, (3) controle das atividades e (4) sua divulgação. Ritemberg (2013) adiciona (5) a tecnologia da informação, (6) efetividade da governança e (7) julgamento profissional.

Figura 1 - Dimensões que influenciam a qualidade dos controles internos

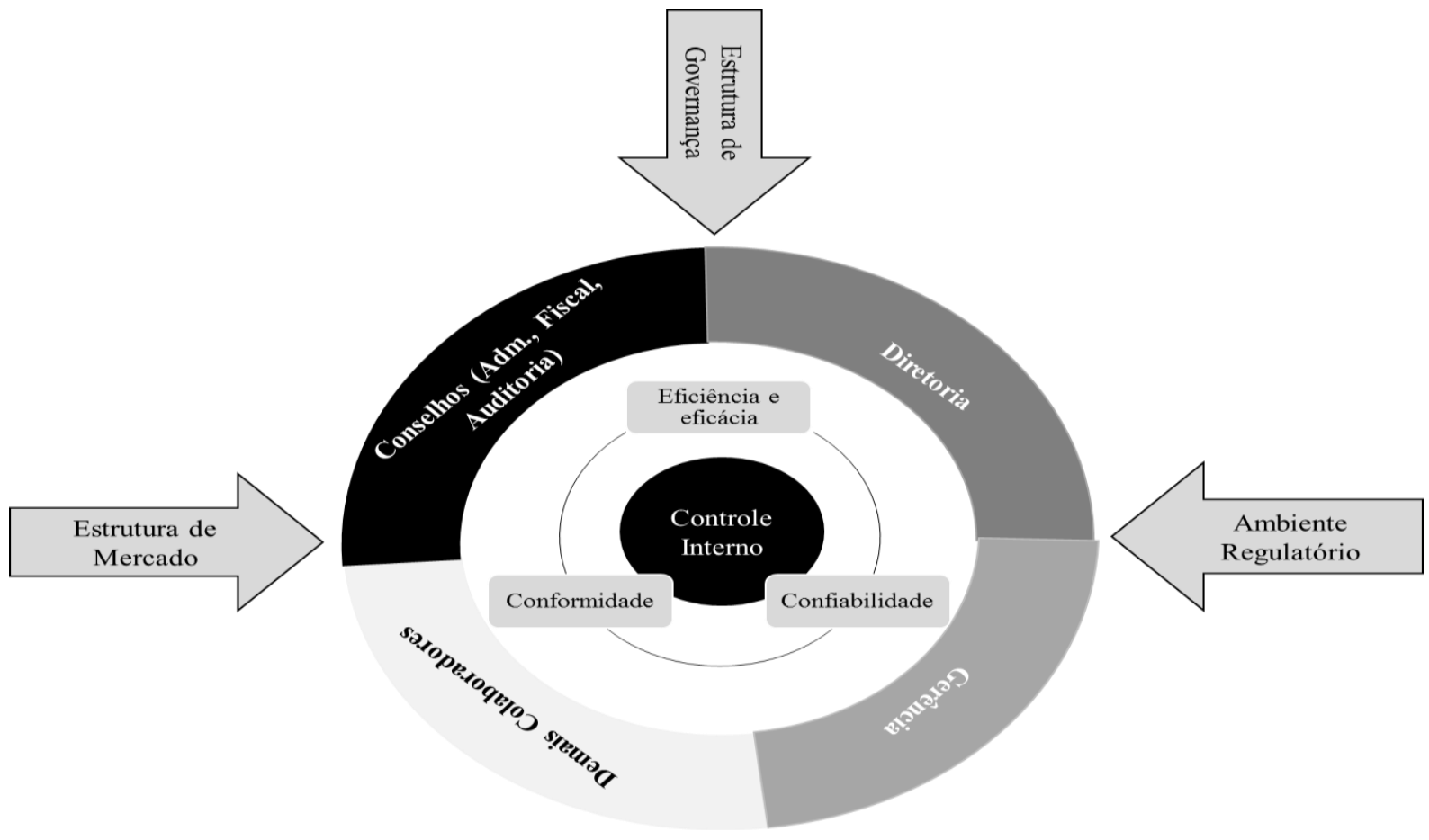

Fonte: Elaborado a partir da combinação entre Jensen \& Meckling (1976), Tysiac (2012), Ritemberg (2013).

Verifica-se que a adequação do controles internos, deve ser balizada por princípios de governança coporativa em um processo permanente de adequação entre as dimensões contidas na Figura 1. Portanto, a estrutura de governança deve estimular a estruturação de um sistema de controle interno orientado por princípios de governança.

\subsection{Divulgação das Deficiências dos Controles Internos no Contexto Brasileiro}

Como os controles internos podem afetar direta e indiretamente os usuários na medida em que suas deficiências possibilitam a expropriação de recursos, sua divulgação 
poderá contribuir para ajustar as expectativas dos mesmos, de modo que eles avaliem mais adequadamente o andamento dos negócios. Jokipii (2010) argumenta que quatro fatores tem sido observados como relevantes na efetividade dos controles internos: (i) estratégia, (ii) o tamanho da firma, (iii) a estrutura organizacional e (iv) a percepção de incerteza. Uma implicação direta disso é que por exemplo, um ambiente de incerteza fará com que as partes envolvidas (stakehoders e shareholders) exigirão uma divulgação mais robusta de informações acerca das deficiências dos controles internos, pois essas podem aumentar ou reduzir ainda mais suas percepções de riscos.

Doyle, Ge e McVay (2005) afirmam que a divulgação das deficiências podem auxiliar: (i) na avaliação do risco de auditoria, (ii) na probabilidade de gerenciamento de resultados, (iii) na precificação das ações, (iv) na qualidade da gestão, entre outras. Desse modo, os reguladores têm estabelecido normas para que as empresas divulguem as deficiências relevantes identificadas ao longo dos exercícios. De acordo com a Resolução CFC 1.210/2009, o profissional de contabilidade, no exercício da auditoria, deverá "comunicar apropriadamente, aos responsáveis pela governança e administração, as deficiências de controle interno que foram identificadas na auditoria das demonstrações contábeis. (p.4)".

Como o auditor tem o objetivo de verificar a adequação das demonstrações contábeis divulgadas, as deficiências dos controles internos podem prejudicar a adequação dos números contábeis em decorrência de uma fraude ou erro. De acordo com o Public Company Accounting Oversigth Board (PCOB), os auditores devem considerar como deficiências relevantes nos controles internos quando encontrarem um ambiente de controle que julgarem aumentar o risco de fraudes e erros, quando verificarem que o sistema de informações e/ou infraestrutura tecnológica apresentam fragilidades significativas, quando a segregação das atividades (responsabilidades) for inadequada ou quando os controles forem alterados frequentemente. Por certo que o julgamento profissional deve pautar a avaliação do auditor quanto às deficiências de controle e seu reporte, quando cabível, sempre pensando nos princípios de governança corporativa (Johnstone, Li, \& Rupley, 2010).

$\mathrm{O}$ que se deprende do posicionamento do $\mathrm{PCOB}$ é que a normatização brasileira segue a mesma linha de raciocínio, pois, o auditor deve divulgar as deficiências ou fragilidades que forem relevantes. No caso da NBC TA 265, o Conselho Federal de Contabilidade destacou o termo relevante, entretanto, o artigo. 25 da instrução CVM 308/1999, vigente e aplicável às empresas listadas no mercado de capitais brasileiro até então, o texto é mais abrangente e afirma que: "o auditor independente deve elaborar e encaminhar à administração e, quando solicitado, ao Conselho Fiscal, relatório circunstanciado que contenha suas observações a respeito de deficiências ou ineficácia dos controles internos e dos procedimentos contábeis da entidade auditada". (COMISSÃO DE VALORES MOBILIÁRIOS, 2016, p.7-8).

A CVM (2016, p.7) destaca ainda que a inexistência de deficiências ou fragilidades nos controles internos são situações "extremamente raras" e nesses casos, o auditor deve apresentar em seu relatório circunstanciado de que que não identificou deficiências ou fragilidades nos controles internos.

A divulgação das deficiências dos controles internos pelas companhias abertas brasileiras está determinado na Instrução CVM 480 de 2009 que “dispõe sobre o registro de emissores de valores mobiliários admitidos à negociação em mercados regulamentados de valores mobiliários". A referida instrução estabelece em seu artigo 21 que "o emissor deverá 
enviar à CVM por meio de sistema eletrônico disponível na página da CVM na rede mundial de computadores, as seguintes informações periódicas (p.9)".

Essa divulgação se dá através do Formulário de Referências, em campo apropriado contendo: “Deficiências e recomendações sobre os controles internos presentes no relatório circunstanciado, preparado e encaminhado ao emissor pelo auditor independente, nos termos da regulamentação emitida pela CVM que trata do registro e do exercício da atividade de auditoria independente". (COMISSÃO DE VALORES MOBILIÁRIOS, 2009, p.108).

\subsection{Pesquisas Anteriores}

Os estudos sobre controles internos no contexto nacional têm se concentrado na discussão teórica acerca das características dos controles, entretanto, alguns estudos buscaram analisar empiramente a questão. Leite e Pinheiro (2015) analisaram a percepção dos auditores e auditados acerca dos efeitos da SOX sobre a estrutura de controle interno. Os autores realizaram um survey com uma amostra intencional, por acessibilidade com 50 empresas auditadas e 93 auditores independentes que atuavam em Big4. Os dados foram analisados através da estatística descritiva e da análise de regressão. Os resultados evidenciaram que, em geral, tanto os auditores, quanto as empresas auditadas verificaram melhorias substanciais com a adoção da SOX, sugerindo que as informações divulgadas passassem a ser mais precisas em decorrência do fortalecimento dos controles internos. Porém, destacam os autores Leite \& Pinheiro (2015, p.15) que a maioria dos respondentes "não apresentaram maior engajamento" na estruturação e melhoria dos controles internos, sobretudo na eliminação de falhas e deficiências. Justificam os autores que, tal observação, pode decorrer do fato de a maioria dos respondentes não terem vivenciado o ambiente préadoção da SOX, logo, não conhecerem as deficiências prévias para que compreendessem a necessidade de melhorias.

Assing, Alberton e Tesch (2016) analisaram o comportamento das fraudes ocorridas em uma amostra de empresas brasileiras e atribuíram às deficiências de controles internos relevância ímpar. Analisando dados de uma amostra de 100 empresas nos anos de 2002 e 2004, verificaram que entre os principais motivos de crescimento dos casos de fraude, destacaram-se: (1) perdas dos valores sociais e morais, (2) impunidade e (3) insuficiência de sistemas de controles. Por sua vez, dentro os sinais de alerta (red flags) observados no período os controles internos foram os principais o que é coerente com a literatura e a normatização sobre o tema. Dado o objetivo do presente trabalho, pode-se verificar que as deficiências dos controles internos compreendem fatores preponderantes na ocorrência de eventos de fraudes e erros, o que reforça sua importância para a estrutura de governança. Pois como a estrutura de governança busca mitigar a expropriação de recursos pelos agentes (conflito de agência) a existência de controles internos, e sua eficácia, tende reduzir a ocorrência desses eventos, logo, a verificação de que foram de fato determinantes na mitigação da ocorrência de fraudes e erros reforça a necessidade de transparência quanto às suas fragilidades e deficiências.

Nessa abordagem, os estudos sobre as deficiências de controles internos são restritos, Teixeira e Cunha (2016) realizaram dois estudos sobre essa temática e com resultados correlatos. A despeito de serem artigos publicados em congressos, cabe sua discussão, pois foram publicados em dois dos principais congressos da área de contabilidade no Brasil. No primeiro, os autores buscaram construir um Índice de Deficiências dos Controles Internos 
(IDCI). Para tanto utilizaram dados de 891 observações do período de 2011 a 2013. De acordo com os autores, 24,8\% dos participantes da amostra apresentaram deficiências nos controles internos no período. Argumentam os autores que, deficiências relacionadas à tecnologia, demonstrações contábeis, litígios, conta específica, subsidiárias e alta administração foram aquelas mais preponderantes. Os autores compararam os seus resultados com os observados por Ge \& McVay (2005) e afirmam que os resultados são divergentes, entretanto, a metodologia utilizada pelos autores é diversa da utilizada no estudo internacional. Ge e McVay (2005) identificaram as principais deficiências relatadas em sua amostra e aquelas com maior ocorrência. Posteriormente, verificaram quais fatores mais afetam a probabilidade de se divulgar uma fragilidade ou deficiência dos controles. De todo modo, os autores trouxeram contribuições para as pesquisas nacionais já que tais estudos são escassos na literatura brasileira.

Em outro estudo, com o mesmo conjunto de dados e resultados comuns em alguns trechos dos artigos, Teixeira e Cunha (2016, p.1) buscaram "analisar a relação entre as combinações dos determinantes das deficiências do controle interno, moderados pelas deficiências existentes, com seus fatores consequentes". Utilizando dados de uma amostra de de 891 observações do período de 2011 a 2013. “Os resultados apontaram que a moderação das deficiências do controle interno sobre os determinantes foi significativa para aumentar o poder de explicação dos honorários de auditoria, delay em auditoria, mudança de opinião e republicação das demonstrações contábeis. (p.1)"

A despeito das limitações e lacunas existentes na literatura nacional, no cenário internacional, diversos estudos empíricos têm sido realizados. O estudo de Ge e McVay (2005) tem sido sistematicamente citado nas pesquisas que os sucederam. Estes autores buscaram identificar quais os tipos de deficiências reportadas pelas empresas de 261 empresas de empresas registradas na SEC. Os autores analisaram dados de 2002 a 2004 e identificaram 439 tipos deficiências reportadas agrupadas nas seguintes categorias (Gráfico 1).

\section{Gráfico 1 - Tipos de deficiências identificadas}

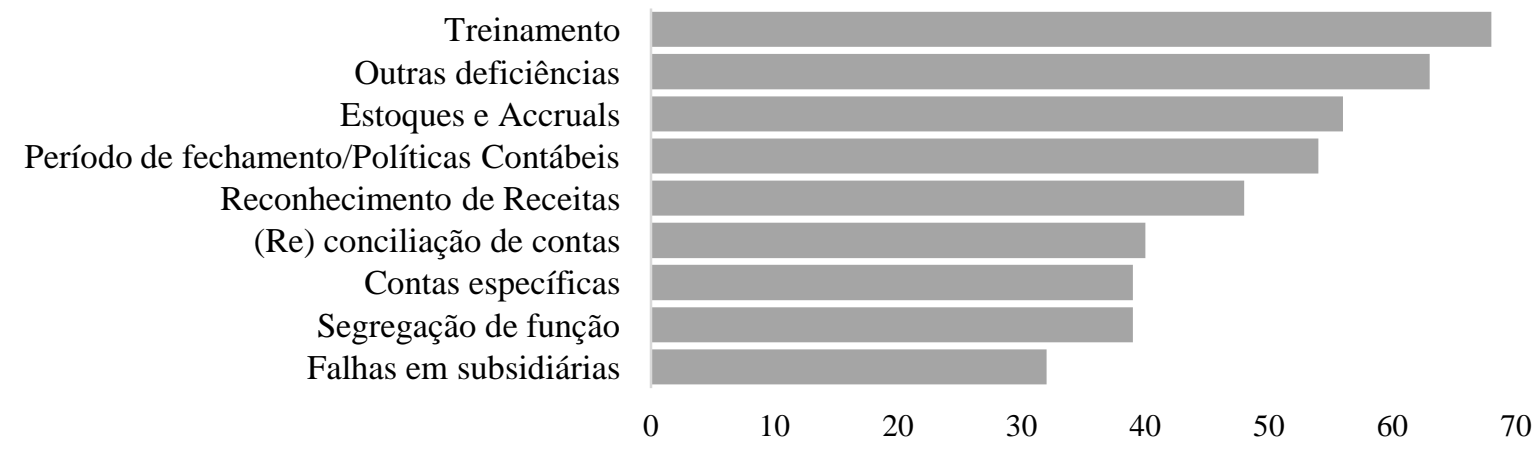

Fonte: Adaptado de Ge \& McVay (2005, p.149)

Posteriormente, os autores analisaram as variáveis determinantes da divulgação de deficiência. Verificaram que o segmento operacional em que a empresa atua e a influência de moeda estrangeira, o tamanho do auditor, o ROA e o Valor Contábil têm efeito significativo e persistente sobre o disclosure das deficiências. Nas três primeiras variáveis, seus efeitos são positivos, evidenciando que elas aumentam a chance de se divulgar deficiências e estão associadas à complexidade dos negócios (segmento operacional e moeda estrangeira), no caso do 
tamanho do auditor, explicam os autores que como tem maiores recursos para identificação de deficiências, a probabilidade de sua divulgação é maior. Já o ROA e o Valor Contábil (Book Value) apresentaram efeito negativo, evidenciando que quanto maior, menor é a divulgação de deficiências de controles internos. Tais resultados são coerentes com a Teoria da Agência em que a estrutura de governança e a estrutura de controle interno contribuirão para o alinhamento dos interesses dos agentes e principais e maximização dos resultados. No caso do Book Value, os autores argumentam que o tamanho da empresa pode explicar o efeito negativo, pois empresas maiores terão maiores recursos para mitigarem suas deficiências de controles.

Outros estudos estrangeiros buscaram estudar sobre as fragilidades e deficiências dos controles internos, destacando-se os seguintes resultados:

- Firmas menores, com crescimento rápido, menor lucratividade, mais complexas ou com reestruturação em andamento tendem a mais divulgações de controles internos (Doyle, Ge, \& McVay, 2007);

- Empresas com maiores deficiências de controles internas tendem a ter comitês de auditorias menos experientes, auditores externos mais independentes identificando mais adequadamente as deficiências (Zhang, Zhou, \& Zhou, 2007);

- Estruturas de governança frágeis resultam em estrutura de controle interno e gestão de risco deficitários (Sarens \& Christopher, 2010).

Além destes, o Quadro 1 apresenta síntese de resultados anteriores de estudos internacionais sobre deficiências de controles internos. 
Quadro 1 - Síntese de estudos empíricos internacionais sobre fragilidades dos controles internos

\begin{tabular}{|c|c|c|c|}
\hline Autor (Ano) & Objetivo & $\begin{array}{c}\text { Classificação da } \\
\text { pesquisa/Amostra/Método }\end{array}$ & Principais resultados \\
\hline Lenard et al. (2016) & $\begin{array}{l}\text { Analisar a relação entre as fragilidades dos } \\
\text { controles internos e o gerenciamento de } \\
\text { resultados operacionais. }\end{array}$ & $\begin{array}{l}\text { Descritiva, documental e com abordagem } \\
\text { quantidade. Dados de } 1.883 \text { empresas do } \\
\text { período de 2004-2010 ( } 7.475 \text { observações). } \\
\text { Análise de regressão. }\end{array}$ & $\begin{array}{l}\text { Existe uma associação positiva entre as fragilidades dos } \\
\text { controles internos e o gerenciamento de resultados através das } \\
\text { operações. }\end{array}$ \\
\hline Huang et al. (2015) & $\begin{array}{l}\text { Analisar o efeito das fragilidades dos } \\
\text { controles internos sobre as ações em } \\
\text { tesouraria. }\end{array}$ & $\begin{array}{l}\text { Descritiva, documental e com abordagem } \\
\text { quantidade. Dados de } 3.909 \text { empresas do } \\
\text { período de 2004-2010 (15.409 observações). } \\
\text { Análise de regressão. }\end{array}$ & $\begin{array}{l}\text { As fragilidades dos controles internos tem efeitos negativos e } \\
\text { significativos sobre sobre o valor das ações em tesouraria. }\end{array}$ \\
\hline Ji, Lu \& Qu (2015) & $\begin{array}{l}\text { Analisar as determinantes e consequências } \\
\text { econômicas da divulgação voluntária das } \\
\text { fragilidades dos controles internos. }\end{array}$ & $\begin{array}{l}\text { Descritiva, documental e com abordagem } \\
\text { quantidade. Dados de } 1.141 \text { empresas do } \\
\text { período de 2010-2011. Análise de } \\
\text { regressão. }\end{array}$ & $\begin{array}{l}\text { A divulgação voluntária sobre as fragilidades dos controles } \\
\text { internos é afetada signficativamente pela estrutura de } \\
\text { governança (e.g. estrutura de propriedade, independência do } \\
\text { conselho e da diretoria, conexões políticas, etc.) }\end{array}$ \\
\hline Jaggi, Mitra \& Hossain (2015) & $\begin{array}{l}\text { Analisar a associação entre as fragilidades } \\
\text { dos controles interno, qualidade da } \\
\text { auditoria e gerenciamento dos resultados. }\end{array}$ & $\begin{array}{l}\text { Descritiva, documental e com abordagem } \\
\text { quantidade. Dados de } 7.172 \text { empresas do } \\
\text { período de 2004-2008. Análise de } \\
\text { regressão. }\end{array}$ & $\begin{array}{l}\text { Existe uma associação positiva entre as deficiências de } \\
\text { controles internos e os accruals discricionários. Entretanto, ser } \\
\text { auditado por uma Big4 gera uma redução dessa proxy de } \\
\text { gerenciamento de resultados. }\end{array}$ \\
\hline Mazza \& Azalli (2015) & $\begin{array}{l}\text { Analisar o efeito da qualidade da auditoria } \\
\text { interna sobre a gravidade e persistência das } \\
\text { deficiências dos controles internos. }\end{array}$ & $\begin{array}{l}\text { Descritiva, documental e com abordagem } \\
\text { quantidade. Dados de } 84 \text { empresas }(4.284 \\
\text { observações). Análise de regressão. }\end{array}$ & $\begin{array}{l}\text { Qualidade da auditoria tem efeito significativo sobre a } \\
\text { grafidade e persistência das deficiências de controles internos, } \\
\text { coerente com a teoria da agência. }\end{array}$ \\
\hline Balsam, Weng \& Lu (2014) & $\begin{array}{l}\text { Analisar o efeito do pacote de remuneração } \\
\text { sobre as fragilidades dos controles internos. }\end{array}$ & $\begin{array}{l}\text { Descritiva, documental e com abordagem } \\
\text { quantidade. Dados de } 569 \text { empresas (3.798 } \\
\text { observações). Análise de regressão. }\end{array}$ & $\begin{array}{l}\text { O pacote de incentivos reduzem as fragilidades dos controles } \\
\text { internos, pois induzem os gestores a fortalecerem os sistemas } \\
\text { de controles internos utilizados pelas emrpresas. }\end{array}$ \\
\hline Lin et al. (2014) & $\begin{array}{l}\text { Analisar a influencia das características do } \\
\text { CEO sobre a qualidade dos controles } \\
\text { internos. }\end{array}$ & $\begin{array}{l}\text { Descritiva, documental e com abordagem } \\
\text { quantidade. Dados de } 4.374 \text { empresas com } \\
\text { gestores de três gerações. Análise de } \\
\text { regressão. }\end{array}$ & $\begin{array}{l}\text { A idade, o gênero e o Enraizamento melhoram a qualidade } \\
\text { dos controles internos, reduzindo as deficiências de controle. }\end{array}$ \\
\hline Mitra, Jagggi \& Hossain (2013) & $\begin{array}{l}\text { Analisar a associação entre o } \\
\text { conservadorismo e as fragilidades dos } \\
\text { controles internos. }\end{array}$ & $\begin{array}{l}\text { Descritiva, documental e com abordagem } \\
\text { quantidade. Dados de } 84 \text { empresas }(1.746 \\
\text { observações) do período de 2004-2009. } \\
\text { Análise de regressão. }\end{array}$ & $\begin{array}{l}\text { As empresas com maiores deficiências de controles internos } \\
\text { apresentam maior grau de conservadorismo condicional, ou } \\
\text { seja, menor qualidade das informações contábeis. }\end{array}$ \\
\hline
\end{tabular}

Fonte: Elaborado pelos autores. 


\section{PROCEDIMENTOS METODOLÓGICOS}

O presente estudo classificou-se como descritivo quanto aos objetivos, documental quanto aos procedimentos e quali-quanti quanto a abordagem do problema. De acordo com Cooper e Schindler (2003), os estudos descritivos são aqueles que buscam apresentar características que possibilitam conhecer melhor o fenômeno estudado. No caso, os tipos de deficiências de controles internos reportados pelas empresas listadas na $[\mathrm{B}]^{3}$ no período de 2010-2015. Quanto aos procedimentos, Raupp e Beuren (2006) definem as pesquisas documentais como aquelas que analisam documentos manuscritos ou não, geralmente em seus originais, mas não exclusivamente. Especificamente, no presente estudo analisou-se os formulários de referência disponíveis no sítio eletrônico da CVM. O estudo classificou-se como quali-quanti, pois analisou o conteúdo dos formulários de referência no que concerne às deficiências de controles internos de modo a categorizá-las. As categorias utilizadas foram as mesmas propostas por Ge e McVay (2005), de modo que se possibilitasse comparar os resultados encontrados. A abordagem quantitativa decorreu da utilização da estatística descritiva e dos testes de diferenças entre os grupos (Kruskall-Wallis).

A amostra inicial do estudo foi composta por 55 empresas listadas na $[B]^{3}$ e que compuseram o IBOVESPA no último trimestre de 2015. Os formulários de referência foram coletados no período de 2010 a 2015, período do qual o mesmo passou a ser disponibilizado no sítio eletrônico da [B] ${ }^{3}$. A amostra final foi composta 32 empresas, que divulgaram alguma informação sobre as deficiências dos controles internos. $O$ total de observações analisadas foram 270, dos quais, 132 referiram-se a declaração de inexistência de deficiências dos controles internos.

De modo a se compreender possíveis associações entre as deficiências de controles internos e características das firmas analisou-se a matriz de correlação e testou-se a hipótese de diferenças entre as médias dos grupos (anos, nível de governança, tipo de auditor e segmento econômico). Para comparar as médias de deficiências entre os anos, as empresas de auditoria, os níveis de governança e os segmentos econômicos, testando-se a hipótese de que não existe diferenças significativas entre as deficiências de controles internos (DC) dos grupos $\left(H_{0}: D C_{i}=D C_{j}=D C_{k}=\cdots=D C_{n}\right)$. A regra de decisão do teste consiste em rejeitar $H_{0}$ quando o p-valor for inferior a $1 \%, 5 \%$ ou $10 \%$. Deste modo, quando o p-valor for superior aos níveis de significância definidos, considerar-se-á que não existe diferença entre os grupos (ano, tipo de auditor, nível de governança, segmento econômico).

\section{ANÁliSE DE DADOS E RESULTADOS}

Inicialmente, os tipos de deficiências de controles (Tabela 1) foram analisados. Observou-se que 23,18\% das deficiências divulgadas referiram-se aquelas relacionadas ao treinamento, seguidos por falhas tecnológicas $(19,56 \%)$, falhas em subsidiárias $(17,39 \%)$, contas específicas $(15,22 \%)$ e segregação de funções (11,59\%), que juntas totalizaram 86,96\% das deficiências divulgadas. Comparativamente, àquelas deficiências divulgadas por Ge e McVay (2005), observou-se uma convergência apenas nos controles internos relativos ao treinamento. Por outro lado, em termos de divergências, observou-se que o Reconhecimento de Receitas (3) e Falhas em Subsidiárias (24) se destacaram.

Na pesquisa de Ge e McVay (2005), as deficiências relativas ao Reconhecimento de Receitas (48) e as Falhas em Subsidiárias (32) figuraram como a quarta de maior representatividade e com menor observância respectivamente. No presente estudo, as falhas 
em subsidiárias foram o terceiro tipo de deficiência com maior observância e aquelas deficiências relativas ao reconhecimento de receitas foram as de menor ocorrência.

Tabela 1 - Estatística descritiva das deficiências de controles internos reportadas pelas empresas da amostra no período de 2010-2015

\begin{tabular}{l|c|c|c|c}
\hline \multicolumn{1}{c|}{ Tipos de Deficiências } & $f i$ & $\mu$ & $\sigma$ & CV \\
\hline Treinamento & 32 & 5,33 & 3,67 & $69 \%$ \\
Falhas Tecnológicas & 27 & 4,50 & 2,26 & $50 \%$ \\
Falhas em Subsidiárias & 24 & 4,00 & 2,97 & $74 \%$ \\
Contas específicas & 21 & 3,50 & 2,17 & $62 \%$ \\
Segregação de Funções & 16 & 2,67 & 2,16 & $81 \%$ \\
(Re) conciliação de Contas & 9 & 1,50 & 1,05 & $70 \%$ \\
Período de Fechamento & 5 & 0,83 & 0,98 & $118 \%$ \\
Reconhecimento de Receitas & 3 & 0,50 & 0,84 & $167 \%$ \\
Acúmulo de Funções & 1 & 0,17 & 0,41 & $\mathbf{2 4 5 \%}$ \\
\hline Deficiências Divulgadas & $\mathbf{1 3 8}$ & $\mathbf{2 3 , 0 0}$ & $\mathbf{1 1 , 0 5}$ & $\mathbf{4 8} \%$ \\
\hline Inexistência de fragilidades relevantes & $\mathbf{1 3 2}$ & $\mathbf{2 2 , 0 0}$ & $\mathbf{6 , 2 0}$ & $\mathbf{2 8} \%$ \\
\hline Total & $\mathbf{2 7 0}$ & $\mathbf{4 5 , 0 0}$ & $\mathbf{8 , 4 9}$ & $\mathbf{1 8 , 8 6 \%}$ \\
\hline Fon
\end{tabular}

Fonte: Dados da pesquisa

Além disso, observou-se que das 270 observações analisadas, 132 referiram-se a divulgação de inexistência de fragilidades relevantes. Conforme Gráfico 2, isso representa $49 \%$ do total de formulários de referências analisados. Essa quantidade de casos sem divulgação de deficiências dos controles internos é uma questão a se destacar. Conforme mencionado pela CVM, trata-se de situação que não deveria acontecer com frequência, pois a probabilidade da estrutura de controle interno demandar ajustes é inerente, principalmente se considerando a necessidade de julgamento permanente por parte dos envolvidos (Tysiac, 2012, \& Rittemberg, 2013).

Por outro lado, conforme observado por Leite e Pinheiro (2015), a despeito de justificarem uma inércia das equipes responsáveis pelos controles internos na eliminação das deficiências dos controles, o elevado volume de casos declarados como inexistência de deficiências pode estar associado a essa característica dos responsáveis pelos controles internos. Entrentanto, outra questão mais relevante, refere-se a independência dos auditores. Responsáveis por avaliar de forma ampla e completa a estrutura de controles e reportar adequadamente ao conselho fiscal, tal fenômeno observado nesse estudo pode sinalizar prejuízos na independência do auditor. Zang, Zhou e Zhou (2007) observaram que a independência é um fator crucial no que tange à fragilidade dos controles, pois auditores mais independentes tenderão a ser mais rigorosos na avaliação dos controles internos. 
Gráfico 2 - Distribuição das deficiências de controles internos por categoria comunicadas pelas empresas da amostra no período de $\mathbf{2 0 1 0 - 2 0 1 5}$

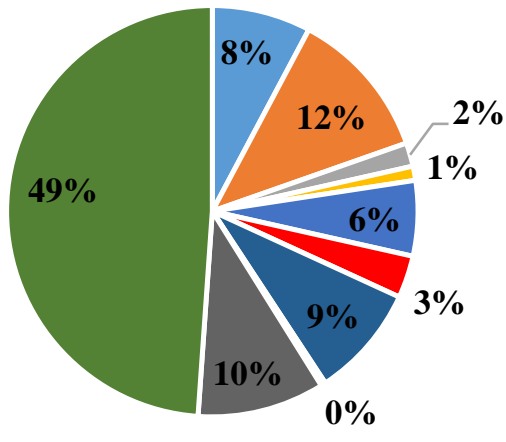

Fonte: Dados da pesquisa.
- Contas específicas

- Treinamento

- Período de Fechamento

- Reconhecimento de Receitas

- Segregação de Funções

- (Re)conciliação de Contas

- Falhas em Subsidiárias

- Acumulo de Funções

- Falhas Tecnológicas

- Inexistência de fragilidades relevantes

Posteriormente, analisou-se a evolução das deficiências ao longo do período (Gráfico 3). Verificou-se uma tendência de decréscimo naquelas que ocorreram com maior frequência (contas específicas, treinamento, falhas em tecnológicas, etc.). Essa redução é importante por diversas questões. A principal é que um dos objetivos da divulgação das deficiências é que hajam ações posteriores que busquem mitigá-las.

\section{Gráfico 3 - Evolução das quantidades de deficiências de controles internos por categoria comunicadas pelas empresas da amostra ao longo do período de 2010-2015}

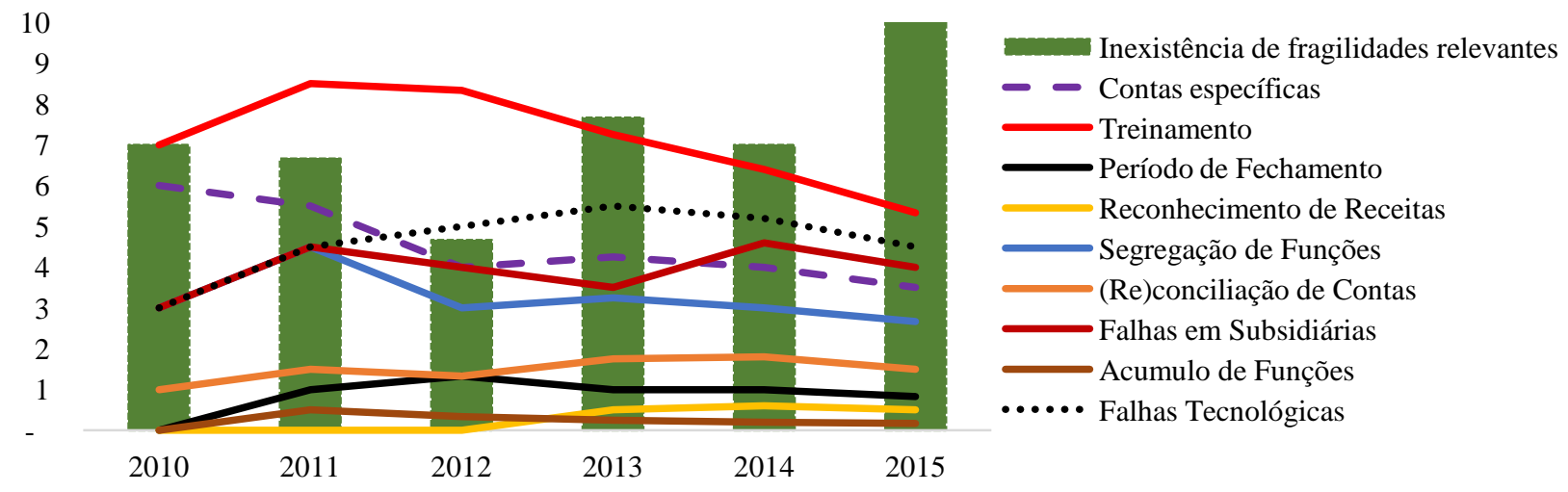

Fonte: Dados da pesquisa

Nota: O total de observações com inexistência de fragilidades relevantes foi dividido por três para melhorar a visualização no gráfico.

Por outro lado, mantendo-se os mesmos níveis, sugere-se que não houve ação mitigadora a posteriori. Nesse contexto, não havendo ações para solucioná-las, tanto os auditores, quanto os órgãos reguladores, são competentes a intervir conforme os mecanismos disponíveis. No caso dos auditores, havendo alguma deficiência que afete significativa nos resultados dos números contábeis, uma opinião qualificada pode ser o mecanismo útil para o enforcement das ações corretivas. No caso do regulador, seu poder de polícia, via imposição de multa e/ou abertura de processo com tal finalidade é uma possibilidade. Em termos quantitativos, verifica-se que os Coeficientes de Variações (CV's) 
das deficiências identificadas foram elevadas (superiores a 50\%), isso significa que possíveis correções e/ou surgimento de novas deficiências dentro de cada categoria foram ocorrendo ao longo do período estudado. Entretanto, em termos médios, esse coeficiente (CV) foi de $48 \%$. Apesar de ser superior ao geralmente aceito como sugerindo um comportamento homogêneo (30\% conforme Fávero et al., 2009) essa variabilidade não foi tão superior. Entretanto, uma questão que se destacou na análise de série temporal foi que no período de 2010 a 2012, anos iniciais da adoção do IFRS, houve uma tendência de decréscimo dos casos de divulgação, de inexistência de deficiências dos contoles, porém, a partir de 2013 essa quantidade aumentou algo em torno de $37,5 \%$.

Quando analisado os dados por empresa de auditoria (Gráfico 4), verificou-se que $71 \%$ dos casos das empresas auditadas pelas não Big4 divulgaram que não identificaram deficiências relevantes e as deficiências identificadas restringiram-se a problemas relativos ao treinamento e fahas tecnológicas. Dentre as empresas de auditoria que menos divulgaram inexistência de deficiências, destacou-se a Ernest Young (21\%). Essa observação é relevante. Primeiro porque pode sinalizar uma maior poder de influência na adequação da estrutura de controles internos. Por outro lado, isso pode sinalizar menor independência, o que implicaria em omissão ou negligência.

Gráfico 4 - Distribuição das deficiências de controles internos por tipo de auditor comunicadas pelas empresas da amostra ao longo do período de 2010-2015

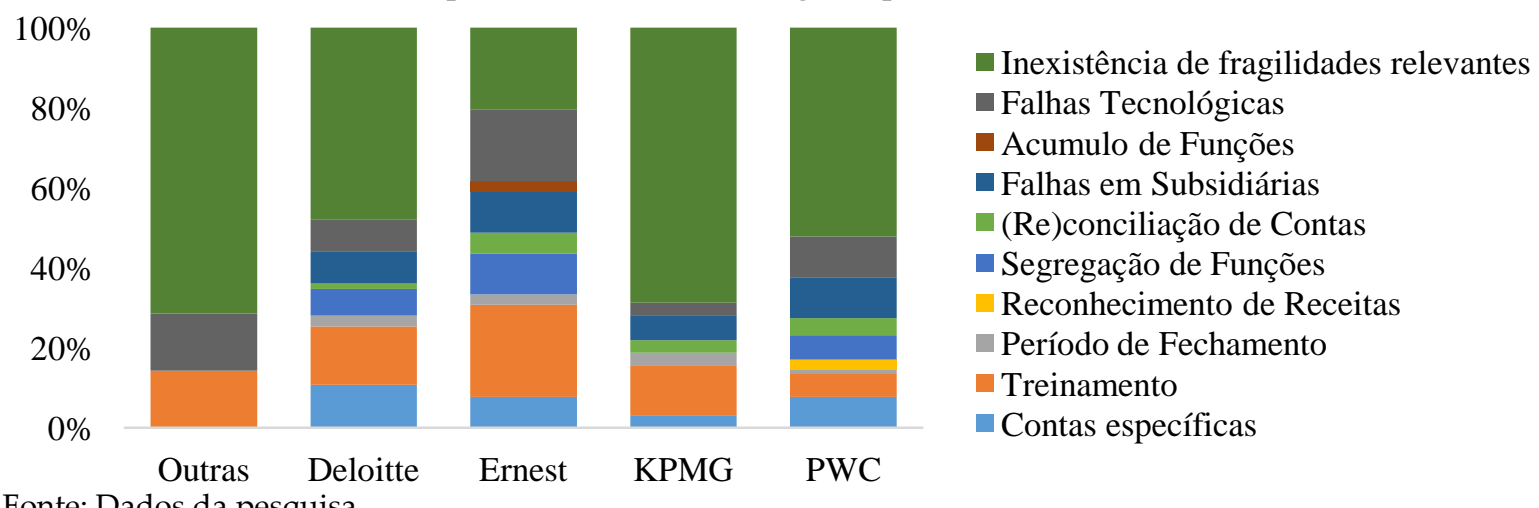

Além disso, nessa empresa, observou-se uma maior diversidade de deficiências identificadas, porém, o treinamento, como já analisado na Tabela 1, foi a deficiência mais observada para esse grupo. Dentre aquelas empresas Big4 que mais divulgaram inexistência de deficiências destacou-se a KPMG. De acordo com os dados coletados, $69 \%$ dos casos referiram a divulgação de inexistência de deficiências. Por se tratar de uma empresa de auditoria deste grupo (Big4) esses resultados são preocupantes. Primeiro que espera-se uma maior independência por parte desses auditores Zhang, Zhou e Zhou (2007), segundo que tal declaração deveria ser um caso raro (CVM, 2016), logo, a observância frequente desses casos pode sinalizar fragilidades tanto na qualidade da auditoria quanto no processo de gestão de riscos da empresa (Sarens \& Christopher, 2010).

Posteriormente, realizou-se a análise setorial das deficiências identificadas (Gráfico 5) observando-se que os setores de Consumo Cíclico e Consumo Não Cíclico foram os mais recorrentes nas categorias de deficiências identificadas. Por outro lado, o Acúmulo de Funções da Alta Gestão foram observados apenas em empresas do setor de consumo não cíclico. Já o Reconhecimento de Receitas foi uma categoria observada apenas nos setores de utilidades públicas, em ambos os casos, se justificam. Segundo Ge e McVay (2007), setores com 
maior complexidade tendem a apresentar maior volume de deficiências. Nas demais deficiências, verificou-se uma diversidade de ocorrências nos demais setores sugerindo que não há associação entre tipos de deficiências e segmentos econômicos específicos.

Gráfico 5 - Distribuição das deficiências de controles internos por segmento econômico comunicadas pelas empresas da amostra ao longo do período de 2010-2015

Inexistência de fragilidades relevantes

Falhas Tecnológicas

Acumulo de Funções da Alta Gestão

Falhas em Subsidiárias

(Re)conciliação de Contas

Segregação de Funções

Reconhecimento de Receitas

Período de Fechamento

Treinamento

Contas específicas

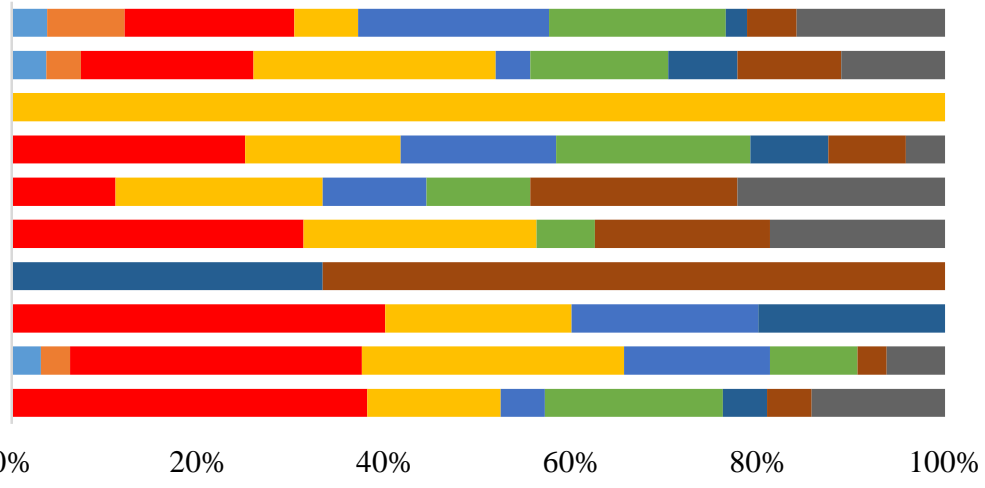

- Bens Industriais

- Construção e Transporte

- Financeiro

- Consumo Cíclico

- Consumo não Cíclico

- Materiais Básicos

Fonte: Dados da pesquisa

Quando analisado por nível de governança (Gráfico 6), verifica-se uma predominância de ocorrência de deficiências no Novo Mercado. Tal resultado parece $a$ priori contraditório, pois a estrutura de governança tem papel importante na mitigação de deficiências de controles internos (Sarens \& Chrstopher, 2010).

Gráfico 6 - Evolução das quantidades de deficiências de controles internos por Nível de Governança comunicadas pelas empresas da amostra ao longo do período de 2010-2015

Inexistência de fragilidades relevantes Falhas Tecnológicas

Acumulo de Funções da Alta Gestão

Falhas em Subsidiárias

(Re)conciliação de Contas

Segregação de Funções

Reconhecimento de Receitas

Período de Fechamento

Treinamento

Contas específicas

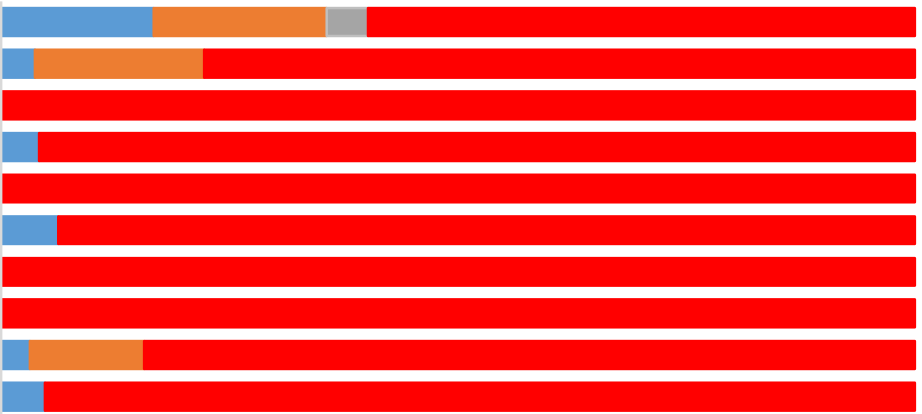

$\begin{array}{lllllllllll}0 \% & 10 \% & 20 \% & 30 \% & 40 \% & 50 \% & 60 \% & 70 \% & 80 \% & 90 \% & 100 \%\end{array}$

Tradicional Nível $1 \square$ Nível $2 \square$ Novo Mercado

Fonte: Dados da pesquisa

Duas questões podem explicar os resultados. Primeiro, a característica da amostra, pois a maioria das empresas que participam do Ibovespa negociam ações do segmento Novo Mercado. Segundo, que as empresas com melhores estruturas de governança tenderão a ser mais transparentes. Além disso, como a maior parte delas são auditadas pelas Big4, essas estarão obrigadas a relatarem à administração as deficiências identificadas sob pena de respoderem processos junto aos órgãos reguladores. 
Na sequência, analisou-se a correlação entre os tipos de deficiências e características das empresas como o segmento econômico, auditor e nível de governança (Tabela 2).

Tabela 2 - Matriz de Correlação de Spearman entre as deficiências de controles, Nível de Governança, Auditor e Segmento Econômico no período de 2010-2015

\begin{tabular}{|c|c|c|c|c|c|c|c|c|c|c|c|c|c|c|c|}
\hline & & 1 & 2 & 3 & 4 & 5 & 6 & 7 & 8 & 9 & 10 & 11 & 12 & 13 & 14 \\
\hline 1 & NGov & 1 & & & & & & & & & & & & & \\
\hline 2 & Auditor & 046 & 1 & & & & & & & & & & & & \\
\hline 3 & SegEcom & $-399^{* * *}$ &,- 005 & 1 & & & & & & & & & & & \\
\hline 4 & TD & $243^{* * *}$ & ,019 &,$- 379^{* * *}$ & 1 & & & & & & & & & & \\
\hline 5 & $\mathrm{CE}$ & , $189^{* *+}$ &,- 077 &,$- 309^{* * *}$ & 649** & 1 & & & & & & & & & \\
\hline 6 & TR & 133 & ,009 &,$- 311^{* * *}$ &, $729^{* * *}$ &, $519^{* *}$ & 1 & & & & & & & & \\
\hline 7 & PF & 107 & ,006 & -023 & $320^{* * *}$ & ,155* & ,193"* & 1 & & & & & & & \\
\hline 8 & RR & 083 & ,002 & 113,- & $244^{* * *}$ & $227^{* * *}$ & 059 & $244^{* *}$ & 1 & & & & & & \\
\hline 9 & $\mathrm{SF}$ & , $152^{*}$ &,- 032 & $-275^{* * *}$ &, $549^{* * *}$ & $621^{* *}$ & $426^{* *}$ & -,046 &,- 036 & 1 & & & & & \\
\hline 10 & $\mathrm{RC}$ & , $146^{*}$ & ,059 &,$- 258^{* *}$ &, $436^{* *}$ & $477^{\text {** }}$ &, $301^{* *}$ & 120 &, $370^{* *}$ &, $381^{* *}$ & 1 & & & & \\
\hline 11 & FS & $210^{* * *}$ & ,004 & -189** & ,604 & $277^{* * *}$ & $177^{*}$ &, $434^{* * *}$ & ,208 & $233^{* *}$ & 292** & 1 & & & \\
\hline 12 & $\mathrm{AF}$ & 048 & 071 & -080 & ,139* & ,207" & $163^{*}$ &,- 011 &,- 009 & $241^{* *}$ &,- 015 &,- 026 & 1 & & \\
\hline 13 & FT & ,094 & ,000 & 128 & ,695** &, $487^{\text {t*t }}$ & $428^{* *}$ &, $406^{* *}$ & ,193 &, $317^{* *}$ & $480^{* *}$ & $306^{* *}$ &,- 027 & 1 & \\
\hline 14 & IDR & $-188^{* * *}$ &,- 086 & ,332** & $-820^{* * *}$ & $-459^{* * *}$ &,$- 584^{* * *}$ & $-215^{* * *}$ &,$- 165^{*}$ &,$- 395^{* *}$ &,$- 291^{* *}$ & - $494^{* * *}$ &,- 095 &,$- 529^{* * *}$ & 1 \\
\hline
\end{tabular}

Nota: TD - Total de deficiências; CE - Contas Específicas; TR - Treinamento; PF - Período de Fechamento; RR Reconhecimento de Receitas; SF - Segregação de Funções; RC - Reconciliação de Contas; FS - Falhas em Subsidiárias; AF - Acúmulo de Funções da Alta Gestão; FT - Falhas Tecnológicas; IDR - Inexistência de Deficiências Relevantes.

A matriz de correlação reforçou o comportamento observado nos gráficos anteriores pois, as deficiências relacionadas ao treinamento $(0,729)$, as falhas tecnológias $(0,695)$, as contas específicas $(0,649)$ e as falhas em subsidiárias $(0,604)$, foram aquelas que apresentaram maiores correlações significativas e positivas com o Total de Deficiências reforçando serem as mais representativas. Em termos de correlação com as características, o Nível de governança e os Segmentos Econômicos apresentaram correlações significativas, porém fracas. Quanto aos segmento econômico, verificou-se correlações negativas, sinalizando que determinados setores reduzem a chance de se divulgar determinadas deficiências. Quanto ao Nível de Governança, verificou-se uma associação negativa com a Inexistência de Deficiência, reforçando uma maior tendência de transparência das empresas listadas em níveis de governança.

Além da correlação entre os tipos de deficiências e o total de deficiências divulgadas, verificou-se que correlações significativas fracas entre alguns tipos de deficiências, por exemplo: Segregação de função e Contas Específicas, Segregação de Função e Treinamento, entre outras (Ver Tabela 2). Essas correlações indicam que um tipo de deficiência está associado a outros, nesse caso, destacou-se a segregação de funções, pois esse tipo de problema é de fato um problema de controle interno sério, presente em muitos casos de fraudes (Di Pietra, McLeay, \& Ronen, 2014; Fourie \& Ackermann, 2013).

Foi verificado se existem diferenças significativas entre os grupos (Tabela 3). Ao longo dos anos, observou-se que não houve diferença significativa entre as quantidades de deficiências em cada categoria. 
Tabela 3 - Estatística do Teste Kruskall-Wallis para diferenças entre os grupos ao longo do período de 20102015.

\begin{tabular}{|c|c|c|c|c|c|c|c|c|}
\hline & \multicolumn{2}{|c|}{ Ano } & \multicolumn{2}{|c|}{ Nível de Governança } & \multicolumn{2}{|c|}{ Auditor } & \multicolumn{2}{|c|}{ Segmento Econômico } \\
\hline & $x^{2}$ & Sig.Assint. & $x^{2}$ & Sig.Assint. & $x^{2}$ & Sig.Assint. & $x^{2}$ & Sig.Assint. \\
\hline Contas específicas & 3,011 & 698 & 8,324 & $0,040^{* *}$ & 4,996 & ,288 & 39,565 & $0,000^{*}$ \\
\hline Treinamento & 738 & ,981 & 5,236 & ,155 & 12,985 & $0,011^{* *}$ & 45,623 & $0,000^{*}$ \\
\hline Período de Fechamento & 1,020 & ,961 & 2,439 & ,486 & 1,682 & ,794 & 9,929 & ,270 \\
\hline Reconhecimento de Receitas & 7,070 & ,216 & 1,449 & ,694 & 4,157 & ,385 & 6,509 &, 590 \\
\hline Segregação de Funções &, 540 & ,991 & 5,662 & , 129 & 6,064 & ,194 & 35,880 & $0,000^{*}$ \\
\hline (Re) conciliação de Contas & 5,205 & 391 & 4,481 & ,214 & 2,339 & 674 & 25,370 & $0,001^{*}$ \\
\hline Falhas em Subsidiárias & 3,383 & 641 & 10,022 & $0,018^{* *}$ & 3,125 &, 537 & 21,663 & $0,006^{*}$ \\
\hline Acumulo de Funções da Alta Gestão & 5,000 & 416 & 478 & ,924 & 6,846 &, 144 & 4,667 & 793 \\
\hline Falhas Tecnológicas & 2,421 & ,788 & 3,805 & ,283 & 7,299 & 121 & 17,777 & $0,023^{* *}$ \\
\hline Total de Deficiências & 1,017 & ,961 & 13,191 & $0,004^{*}$ & 6,889 & ,142 & 41,885 & $0,000^{*}$ \\
\hline Inexistência de Deficiências Relevantes & ,256 & ,998 & 9,788 & $0,020^{* *}$ & 18,144 & $0,001^{*}$ & 43,050 & $0,000^{*}$ \\
\hline
\end{tabular}

Fonte: Dados da pesquisa

Nota: ${ }^{*}{ }^{* *},{ }^{* *}$ Significante estatisticamente ao nível de $1 \%, 5 \%$ e $10 \%$.

$\mathrm{Na}$ análise comparativa entre as empresas que estão em algum nível de governança e as demais, observou-se que apenas entre as deficiências com contas específicas e falhas em subsidiárias, pode-se verificar diferenças significativas ao nível de $5 \%$. Na sequência, comparou-se por tipo de auditoria e verificou-se que, apenas nas deficiências relacionadas ao treinamento e a divulgação de inexistência de deficiências, foram observadas diferenças significativas ao nível de 5\% e 1\%, respectivamente.

Em última análise, comparou-se a existência de diferença entre os segmentos econômicos e verificou-se a existência de diferenças estatisticamente significativas em quase todas as comparações, ao nível de $1 \%$, o que sugere existir diferenças entre os segmentos econômicos, corroborando os resultado apresentados na Gráfico 5.

\section{CONSIDERAÇÕES FINAIS}

O objetivo do estudo foi identificar os tipos de deficiências de controles internos reportadas pelas empresas brasileiras listadas na $[\mathrm{B}]^{3}$ e que fizeram parte do IBOVESPA no último trimestre de 2015. O estudo de natureza de descritiva, documental e com abordagem quali-quanti, analisou dados de 32 empresas coletados a partir do Formulário de Referências, disponível no sítio eletrônico da CVM e resultando em uma amostra final com 270 observações dos quais, 132 referiram-se a declaração de inexistência de deficiências e o restante a deficiências específicas nos controles internos. Dentre os principais resultados, observou-se que $49 \%$ das observações referiram-se a declaração de inexistência de deficiências, o que parece ser incoerente com a expectativa da própria CVM, quando através de Oficio Circular enviado aos regulados, afirma que tais situações são raras. Dentre as deficiências dos controles internos reportadas destacaram-se, por ordem de representatividade: Treinamento (23\%); Falhas tecnológicas (20\%); Falhas em subsidiárias (17\%); Contas Específicas (15\%) e Segregação de Funções (12\%).

Comparando os resultados encontrados com a distribuição de frequência observada no estudo de Ge e McVay (2005), verificou-se convergência nas deficiências reportadas relativas ao treinamento. Por outro lado, dentre as categorias com menor quantidade de observações no presente estudo e que apresentaram-se relevantes no estudo anterior, destacou-se aquelas deficiências relacionadas ao Reconhecimento de Receitas. 
Em termos de homogeneidade e associação das deficiências reportadas com as características das empresas participantes da amostra, verificou-se que as deficiências mais representativas apresentaram significância estatística nos coeficientes de correlações de Spearman. Apesar dos respectivos coeficientes serem de nível médio (entre $60-80 \%$ ) o resultado sugere que outros fatores tem influencia na probabilidade de se divulgar deficiências nos controles internos, o que é coerente com a literatura estrangeira (Doyle, Ge, $\& \mathrm{McV} a y, 2007)$. Fatores como o nível de governança, o tipo de auditor e o segmento econômico, podem influenciar na probabilidade de chances de se divulgar uma deficiência de controle interno (Zhang, Zhou, \& Zhou, 2007).

Sobre esse segundo aspecto, o presente estudo se restringiu à utilização do coeficiente de correlação de Spearman e o teste Kruskall-Wallis para diferenças entre os grupos e o que se observou foi que não existe diferenças significativas entre os anos na maioria das deficiências. Os níveis de governança têm um efeito mitigador no volume geral de deficiências, mas um efeito positivo sobre deficiências específicas. O segmento econômico apresenta diferenças significativas nas deficiências reportadas e por fim, o tipo de auditor apresentou diferença significativa apenas nas deficiências relacionadas aos treinamentos e nas declarações de inexistência de deficiências.

O presente estudo contribui com a literatura sobre o tema na medida em que apresenta um panorama das deficiências dos controles internos reportadas pelas empresas com maior volume de negociações em bolsa na $[\mathrm{B}]^{3}$. Coerente com a literatura consultada, observouse que as empresas divulgam as informações de forma incompleta, pois a proporção de declaração de inexistência de deficiências sugere uma anomalia e exigindo ações emergenciais por parte dos reguladores. Além disso, como não se observou diferenças significativas ao longo dos anos, sugere-se a ocorrência de repetição dos problemas ou não correção dos mesmos. Deste modo, um ambiente de maior enforcement dos agentes econômicos de modo a incentivá-las a exercerem um julgamento mais apropriado quanto aos controles internos e estimulá-los a se comprometerem com a correção das deficiências reportadas, é uma necessidade urgente. Como já observamos ao longo da história, as fragilidades dos mecanismos de controle internos e externos dos agentes econômicos pode nos levar a presenciarmos mais e mais casos de fraudes como aqueles dos anos 2000.

A despeito das contribuições, o presente estudo apresenta limitações, destacando-se: (i) a restrição amostral, (ii) a técnica de análise e (iii) a ausência da análise de relações de causalidade. Deste modo, sugere-se: ampliar a amostra, utilizar-se de técnicas inferenciais que possibilitem a análise das determinantes da divulgação. Além disso, compreender, em profundidade, as características das empresas que declararam inexistirem deficiências dos controles internos, é relevante dada a sugestão de omissão iminente por parte da administração e dos auditores responsáveis pelas mesmas.

\section{REFERÊNCIAS}

Aghion, P., \& Holden, R. (2011). Incomplete contracts and the theory of the firm: What have we learned over the past 25 years?. Journal of Economic Perspectives, 25(2), 181-97.

AICPA - American Institute of Certified Public Accountants. (2016, December). An Examination of an Entity's Internal Control Over Financial Reporting That Is Integrated With an Audit of Its Financial Statements. AT Section 501. Retrieved Janeiro 10 ,

2017,

from 
http://www.aicpa.org/Research/Standards/AuditAttest/DownloadableDocuments/AT00501.pdf.

Assing, I., Alberton, L., \& Tesch, J. M. (2008). O comportamento das fraudes nas empresas brasileiras. Revista da FAE, 11(2). Recuperado em 20 janeiro, 2016 de http://www.fae.edu/publicacoes/fae_v11_2/13_ildefonso_luiz.pdf

Ball, Ray; Brown, Philip. An empirical evaluation of accounting income numbers. Journal of accounting research, p. 159-178, 1968.

Balsam, S., Jiang, W., \& Lu, B. (2014). Equity incentives and internal control weaknesses. Contemporary Accounting Research, 31(1), 178-201.

Beaver, W. H. (1968). The information content of annual earnings announcements. Journal of accounting research, 67-92.

Borgerth, V. M. C. (2012). SOX: entendendo a Lei Sarbanes-Oxley. São Paulo: Cengage Learning, 93.

Brickley, J. A., \& Zimmerman, J. L. (2010). Corporate governance myths: comments on Armstrong, Guay, and Weber. Journal of Accounting and Economics, 50(2-3), 235-245.

Brown, L. D., \& Caylor, M. L. (2009). Corporate governance and firm operating performance. Review of quantitative finance and accounting, 32(2), 129-144.

CFC - Conselho Federal de Contabilidade. (2009, Novembro 27). Resolução 1.210/2009 Aprova a NBC TA 265 - Comunicação de Deficiências de Controle Interno. Brasília.

Cheng, M., Dhaliwal, D., \& Zhang, Y. (2013). Does investment efficiency improve after the disclosure of material weaknesses in internal control over financial reporting? Journal of Accounting and Economics, 56(1), 1-18.

Cooper, D. R., \& Schindler, P. S. (2003). Métodos de Pesquisa em Administração, McGraw Hill Brasil. Tradução de Luciana de Oliveira Rocha - 7ª Edição. Porto Alegre: Bookman, 2003.

CVM - Comissão de Valores Mobiliários. (1999, Maio 19). Instrução CVM 308 - Dispõe sobre o registro e o exercício da atividade de auditoria independente no âmbito do mercado de valores mobiliários, define os deveres e as responsabilidades dos administradores das entidades auditadas (...). Rio de Janeiro, RJ, Brasil.

CVM - Comissão de Valores Mobiliários. (2009, Dezembro 09). Instrução CVM 480 - Dispõe sobre o registro de emissores de valores mobiliários admitidos à negociação em mercados regulamentados de valores mobiliários. Rio de Janeiro, RJ, Brasil.

CVM - Comissão de Valores Mobiliários. (2016, Janeiro 21). OFÍCIO-

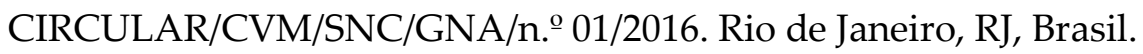

Di Pietra, R., McLeay, S., \& Ronen, J. (Eds.). (2014). Accounting and regulation: New insights on governance, markets and institutions. Springer Science \& Business Media.

Doyle, J. T., Ge, W., \& McVay, S. (2007). Accruals quality and internal control over financial reporting. The accounting review, 82(5), 1141-1170.

Dye, R. A., \& Sridhar, S. S. (2008). A positive theory of flexibility in accounting standards. Journal of Accounting and Economics, 46(2-3), 312-333.

Fávero, L. P. L., Belfiore, P. P., Silva, F. L. D., \& Chan, B. L. (2009). Análise de dados: modelagem multivariada para tomada de decisões.

Fourie, H., \& Ackermann, C. (2013). The impact of COSO control components on internal control effectiveness: an internal audit perspective. Journal of Economic and Financial Sciences, 6(2), 495-518. Recuperado em 01 junho, 2016 de http://journals.co.za/content/jefs/6/2/EJC142871 
Ge, W., \& McVay, S. (2005). The disclosure of material weaknesses in internal control after the Sarbanes-Oxley Act. Accounting Horizons, 19(3), 137-158.

Hammersley, J. S., Myers, L. A., \& Shakespeare, C. (2008). Market reactions to the disclosure of internal control weaknesses and to the characteristics of those weaknesses under Section 302 of the Sarbanes Oxley Act of 2002. Review of Accounting Studies, 13(1), 141-165.

Hay, D., Knechel, W. R., \& Ling, H. (2008). Evidence on the impact of internal control and corporate governance on audit fees. International Journal of Auditing, 12(1), 9-24.

Huang, P., Guo, J., Ma, T., \& Zhang, Y. (2015). Does the value of cash holdings deteriorate or improve with material weaknesses in internal control over financial reporting?. Journal of Banking \& Finance, 54, 30-45.

Jaggi, B., Mitra, S., \& Hossain, M. (2015). Earnings quality, internal control weaknesses and industry-specialist audits. Review of Quantitative Finance and Accounting, 45(1), 1-32.

Jensen, M. C., \& Meckling, W. H. (1976). Theory of the firm: Managerial behavior, agency costs and ownership structure. Journal of financial economics, 3(4), 305-360.

Jensen, M. C.; Meckling, W. H. (1994). The nature of man. Journal of Applied Corporate Finance, Boston, 7(2), 4-19.

Ji, X. D., Lu, W., \& Qu, W. (2017). Determinants and economic consequences of voluntary disclosure of internal control weaknesses in China. Journal of Contemporary Accounting \& Economics, 11(1), 1-17.

Johnstone, K., Li, C., \& Rupley, K. H. (2010). Changes in corporate governance associated with the revelation of internal control material weaknesses and their subsequent remediation. Contemporary Accounting Research, 28(1), 331-383.

Jokipii, A. (2010). Determinants and consequences of internal control in firms: a contingency theory based analysis. Journal of Management \& Governance, 14(2), 115-144.

Porta, R. L., Lopez-de-Silanes, F., Shleifer, A., \& Vishny, R. W. (1998). Law and finance. Journal of political economy, 106(6), 1113-1155. Recuperado em 10 de janeiro, 2013 de http://www.jstor.org/stable/10.1086/250042

Leite, D. U.; Pinheiro, L. E. T. (2015). Percepção dos Auditores Independentes e Auditados sobre a Aplicação da Lei Sabanes Oxley nos Controles Internos. IX Congresso ANPCONT. Curitiba: [s.n.]. 2015. p. 1-19.

Lenard, M. J., Petruska, K. A., Alam, P., \& Yu, B. (2016). Internal control weaknesses and evidence of real activities manipulation. Advances in accounting, 33, 47-58.

Lin, Y. C., Wang, Y. C., Chiou, J. R., \& Huang, H. W. (2014). CEO characteristics and internal control quality. Corporate Governance: An International Review, 22(1), $24-42$.

Marques, V. A., Aires, D. B. B., Patrício, N., Cerqueira, P., da Silva, L. K. C., \& Fernandes, H. Dinâmica das republicações das demonstrações contábeis no período de 1997-2012 Financial restatement trends in Brazil from 1997-2012.

Mazza, T., \& Azzali, S. (2015). Effects of internal audit quality on the severity and persistence of controls deficiencies. International Journal of Auditing, 19(3), 148-165.

Mitra, S., \& Hossain, M. (2011). Corporate governance attributes and remediation of internal control material weaknesses reported under SOX Section 404. Review of Accounting and Finance, 27(9), 846-877.

Mitra, S., Jaggi, B., \& Hossain, M. (2013). Internal control weaknesses and accounting conservatism: evidence from the post-Sarbanes-Oxley period. Journal of Accounting, Auditing \& Finance, 28(2), 152-191. 
PCAOB - Public Company Accounting Oversight Board. (2007, October 17). An Audit of Internal Control that is Integrated With An Audit of Financial Statements: Guidance for Auditor of Smaller Public Companies. Washington.

Raupp, F. M.; Beuren, I. M. (2006). Metodologia Aplicável às Ciências Sociais. In: BEUREN, I. M. Como elaborar trabalhos monográficos em Contabilidade: teoria e prática. São Paulo: Atlas.

Rittenberg, L. E. (2013). COSO 2013 a reflection of the times: the long-awaited Internal Control-Integrated Framework update aims to help organizations better design and implement controls, with an eye toward today's business challenges. Internal Auditor, 70(4), 60-65.

Sarens, G., \& Christopher, J. (2010). The association between corporate governance guidelines and risk management and internal control practices: Evidence from a comparative study. Managerial Auditing Journal, 25(4),569-577.

Teixeira, S. A., \& DA CUNHA, P. R. (2015). Efeito Moderador das deficiências do controle interno na relação entre seus determinantes e consequentes. XVI Congresso USP de Contabilidade e Controladoria. São Paulo: [s.n.]. p. 1-22.

Teixeira, S. A.; Cunha, P. R. (2019). Índice de Deficiências do Controle Interno: Análise de Empresas Brasileiras Listadas n BM\&FBovespa. X Congresso ANPCONT. Ribeirão Preto: [s.n.]. p. 1-19.

Tysiac, K. (2012). Internal control, revisited: Prominent COSO officials discuss proposed updates to framework.. Journal of Accountancy, 213(3), 24. Recuperado em 16 de fevereiro, 2017

de http://www.journalofaccountancy.com/issues/2012/mar/20114943.html

Zhang, Y., Zhou, J., \& Zhou, N. (2007). Audit committee quality, auditor independence, and internal control weaknesses. Journal of accounting and public policy, 26(3), 300-327. 